\title{
Science Academies' Refresher Course in Foundations of Physical Chemistry and its Applications
}

\author{
at \\ Indian Women Scientists' Association (IWSA) \\ $\mathrm{ICICI}$ Multipurpose Hall \\ Sector 10-A, Dr. Mar Theophilus Marg, Vashi, Navi Mumbai 400703 \\ December 15-30, 2017 \\ Sponsored by Indian Academy of Sciences, Bengaluru \\ Indian National Science Academy, New Delhi \\ The National Academy of Sciences, India, Allahabad
}

Physical Chemistry is the branch of chemistry that deals with the mechanism, the rate and the energy transfer that occur when matter undergoes a change. Understanding the key concepts of physical chemistry is essential for solving practical problems in research and industrial applications. A brief outline of the course is as follows: Quantum chemistry and molecular structure, chemical thermodynamics and applications, electrochemistry and applications, physical chemistry principles involved in analytical chemistry, physical organic chemistry, catalysis, interfacial chemistry and chemical kinetics. The course will comprise of lectures, tutorials and experiments.

Applications are invited from teachers with experience in teaching undergraduate and postgraduate courses in chemistry. Maximum 25 applications will be considered and teachers who wish to participate in the Refresher Course may apply through proper channel with the following details: name, date of birth, gender, Email, official and residential addresses, telephone numbers, academic qualifications, courses taught, affiliation, positions held and tenure. It is also essential to submit a brief statement (between 250 and 500 words) as to why they think the Course will help to improve their classroom teaching of Physical Chemistry. Applications should be submitted ONLINE by clicking the following link:

http://web-japps.ias . ac . in: 8080/Refreshcourse/RCFXP. jsp

A printed copy of the application approved by the Head of the institution should be sent by speed post to: Dr. Shyamala Bharadwaj, Secretary, IWSA, Indian Women Scientists' Association, Sector 10-A, Dr. Mar Theophilus Marg, Vashi, Navi Mumbai 400703. Outstation candidates will be provided local hospitality and round trip bus/train (three-tier AC) fare by the shortest route. Please note that participants have to attend the full duration of the Course. Arrival: December 14 and Departure: December 31, 2017.

Course Director: Dr K Indira Priyadarsini, Head, Chemistry Division, Bhabha Atomic Research Centre, Trombay, Mumbai 400085. (Email: kindira@barc.gov.in)

Course Coordinator: Dr. Shyamala Bharadwaj, Ex-Head, Fuel Cell Materials and Catalysis Section, Chemistry Division, Bhabha Atomic Research Centre, Mumbai 400085

(Email: shyamala.bharadwaj@gmail.com).

Last date for receipt of applications: October 15, 2017. 